\title{
Training biochemistry undergraduate students to be teachers
}

Granjeiro, P.A. ${ }^{1}$, Ribeiro, R.I.M.A. ${ }^{1}$, Silva, J.A. ${ }^{1}$, Martins-Santos, M.E.S. ${ }^{1}$; Torres, B.B. ${ }^{2}$

${ }^{1}$ Curso de Bioquímica, UFSJ, Divinópolis, Minas Gerais, Brasil

${ }^{2}$ Departamento de Bioquímica, IQ, USP, São Paulo, São Paulo, Brazil

In the last few decades the economic revolution has contributed for significant changes in the global scene. The speed and mobility of the information have fortified the competition and increased the competitiveness through the knowledge applied to the science and technological innovation. In this context, in 2008, a graduation course of Biochemistry at UFSJ was created, with the objective to form professionals to research and education in Biochemistry and Molecular Biology. One of the tools used to develop the skills of education of our students is their participation in an optional discipline aiming at developing and implementing practical and theoretical winters courses for High School students. The content of the discipline consists of choosing themes, selecting and organizing the topics, preparing written material, establishing the methodological strategies, planning the evaluation tools and, finally, as teachers, conducting the course. In the last two years the themes consisted in free radicals, bioactives, bioenergy, DNA, biotechnology of microorganisms, genetics of cancer, cellular therapy, and medicinal chemistry. The evaluation of the experience by biochemistry and high school students was very positive. Biochemistry students considered this experience to be unique and recommended it to their schoolmates; the high school students gave very high scores to the courses and the teachers. In conclusion this course was a great experience for both undergraduate students that might become teachers and for high school students that have rare opportunity to participate in science and technology practical classes, which are normally insufficient in their formation.

Key words: biochemistry students, high school students, teacher, winter course, science. 